\title{
Are There Patients with Inflammatory Disease Who Do Not Respond to Prednisone?
}

\begin{abstract}
"Failure to observe the expected effects of prednisone therapy should bring to mind the fact that a very rare patient may lack the hepatic enzyme system that converts prednisone to prednisolone, its active metabolite; the keto group at position 11 must be converted to a hydroxyl group before any glucocorticoid activity is exhibited. Accelerated catabolism of the active metabolite may also result in clinical effects below those expected."
\end{abstract}

Might there be patients with inflammatory disorders who do not respond clinically as expected to prednisone but respond to prednisolone? Clinical medicine was transformed when corticosteroids were synthesized and made available for clinical use in the $1950 \mathrm{~s}^{2,3}$; this is considered one of the landmarks in medicine ${ }^{3}$. [It seems appropriate that this work led to the awarding of the Nobel Prize to Philip S. Hench, $\mathrm{MD}$, (the only rheumatologist to receive a Nobel Prize) and collaborators.] While we now know that corticosteroids are effective for certain patients with inflammatory diseases, there is no incontrovertible evidence to support uniform consensus for the selection of preparation, dosage, and duration for patients with differing conditions ${ }^{4-7}$. Use of corticosteroids remains more art than science. Indeed, some of us learned and taught that there were some patients with inflammatory conditions who responded poorly to prednisone but did well on methylprednisolone. This was articulated by John Decker, MD, a distinguished and authoritative rheumatologist, director of the US National Institute of Arthritis and Metabolic Diseases, National Institutes of Health, and President of the American Rheumatology Association [now American College of Rheumatology (ACR)].

Unresponsiveness to prednisone is poorly studied, poorly documented in the literature, largely limited to experience and anecdote, and perhaps not widely known nor accepted, particularly among younger rheumatologists. One of us informally surveyed a small number of rheumatologists at the October 2009 ACR meeting; while the majority who trained with contemporaries of Dr. Decker "knew" this ("I'm aware of the concept in the lore of rheumatology; that's why we're Masters!", said a former rheumatology division chief and department of medicine chair), a sizeable minority of prominent rheumatologists had no familiarity with this notion.
We briefly describe several of our patients who illustrate this concept, review the literature, and suggest the validity of this observation; this would have important clinical relevance - implying that certain prednisone-nonresponsive patients with inflammatory diseases be offered trials of methylprednisolone.

A 25-year-old man with juvenile rheumatoid arthritis (JRA) who presented with a disease flare and was treated with up to $60 \mathrm{mg}$ prednisone orally daily for 3 weeks, with no response nor Cushingoid changes, improved and developed Cushingoid changes within days of receiving $48 \mathrm{mg}$ methylprednisolone daily. A 67-year-old woman with polymyalgia rheumatica [erythrocyte sedimentation rate (ESR) $45 \mathrm{~mm} / \mathrm{h}$ ], who was unresponsive to prednisone 40 $\mathrm{mg}$ orally daily and showed no signs of hypercorticism, became asymptomatic with normal ESR when switched to prednisolone $40 \mathrm{mg}$ orally daily, but reported insomnia and weight gain of 15 pounds. A 32-year-old woman whose JRA flared and was treated with $12.5 \mathrm{mg}$ prednisone daily, with neither improvement nor Cushingoid changes after 6 weeks, improved and developed physical consequences of hypercorticism after 2 weeks methylprednisolone $48 \mathrm{mg}$ daily; these were sustained taking $12 \mathrm{mg}$ methylprednisolone daily. In a young woman with florid lupus nephritis who was started on $120 \mathrm{mg}$ prednisone daily, without improvement and without emergence of Cushingoid features, showed prompt clinical response and development of Cushingoid features after taking methylprednisolone $80 \mathrm{mg}$ daily.

Have we not all encountered patients treated successfully with parenteral methylprednisone, usually in the hospital, who deteriorated when subsequently placed on equivalent doses of prednisone? Or patients not responding as expected to prednisone who then improved when treated with methylprednisolone, usually in the hospital?

Are there data to support this interpretation? Early studies found that corticosteroids such as cortisone and prednisone were inherently inactive; they needed to be converted in the body to their active metabolites cortisol and prednisolone, respectively ${ }^{8}$. This conversion occurs primarily in the liver by the enzyme 11 beta-hydroxysteroid dehydrogenase type 1 (11ß-HSD1). Lack of enzyme activity leads to impaired conversion and poor availability of the active steroid molecule. In such instances treatment with prednisolone or methylprednisolone, already in an active form, 
may be effective. Limited studies in normal individuals and patients with liver disease are instructive. Several studies have documented impaired conversion of prednisone to prednisolone in patients with liver disease and suggested that prednisolone be used preferentially in these conditions ${ }^{9-11}$; a single report including 4 patients with liver disease, however, noted impairment of conversion of cortisone to cortisol but not prednisone to prednisolone ${ }^{12}$. These variable observations may reflect not only steroid metabolism in the liver but also hepatic elimination and protein binding, which may be affected differentially by severity of liver disease ${ }^{9}$. Although conversion of prednisone to prednisolone was generally impaired in patients with liver disease, serum concentrations may be maintained because of slower elimination. One of these reports found that 2 of 10 normal controls showed unusually low plasma levels of prednisolone after administration of $10 \mathrm{mg}$ prednisone; bioavailability of prednisolone after ingestion of oral prednisone ranged from $22 \%$ to $120 \%$ in the 10 normal subjects; the authors attributed this to differing rates of hepatic conversion of prednisone to prednisolone in healthy subjects ${ }^{11}$. Also, there are patients who have deficiency of the enzyme 11ß-HSD1, which is needed to convert prednisone to prednisolone. This condition, termed acquired cortisone reductase deficiency, ACRD, was recognized in 1984 as a partial deficiency of $11 \beta-H S D 1^{13}$. Eleven patients have been identified; their cortisol deficiency led to activation of the hypothalamic-pituitary axis with resultant clinical signs of androgen excess (sharing overlapping features with polycystic ovarian syndrome). The most recent edition of the authoritative Goodman and Gilman pharmacology text, commenting about patients with liver disease and ACRD, recommended that "in settings in which this enzymatic activity is impaired, it is prudent to use steroids that do not require enzymatic activation (e.g., hydrocortisone and prednisolone rather than cortisone or prednisone)" 14 . These observations, we think, support the possibility that there are some patients, both normal and with liver disease (and perhaps other diseases), who may not optimally metabolize or respond clinically to prednisone.

Might there be other factors contributing to clinically observed unexpected unresponsiveness to prednisone (or cortisone)? Serum levels of prednisolone after prednisone administration may not be the only determinant of the clinical effects of steroids. 11ß-HSD1 may modulate the levels of both endogenous and exogenous steroids at the tissue level. This is suggested by the following observations. 11ß-HSD1 is ubiquitous in skin, bones, the central nervous system, adipose tissues, and in other organs responsive to endogenous cortisol ${ }^{15}$. 11ß-HSD1 activity has been demonstrated in synovial fluid of patients with rheumatoid arthritis and its level shown to correspond with inflammatory markers like ESR ${ }^{16}$. Recently, polymorphisms within the 11ß-HSD1 gene and the gene coding for hexose 6 phosphate dehydrogenase (a coenzyme that supplies reducing equiva- lents to 11ß-HSD1) have been identified with a population prevalence of $3 \%$ and $4 \%$, respectively. These resulted in reduced or absent 11ß-HSD1 activity in cultured cells ${ }^{17}$. Subsequent studies also found a high population prevalence of these polymorphisms ${ }^{18}$. Since we know that genetic polymorphisms affect the metabolism of drugs we use, such as warfarin and azathioprine, it is not unreasonable to consider this might also occur for prednisone.

Might there then be patients with inflammatory disorders who do not respond clinically as expected to prednisone but respond to prednisolone? We think so. We believe we have encountered such patients. We interpret the cited literature as consistent with and supportive of this notion. We suspect prednisone unresponsiveness when we do not observe the expected clinical response at reasonable doses of prednisone, when patients who initially responded to methylprednisolone relapse after being placed on prednisone, and when these patients do not manifest the anticipated physical and metabolic changes of corticosteroid administration (Cushingoid features, increase in appetite, weight gain, insomnia, leukocytosis, eosinopenia, and lymphopenia). We offer such patients a trial of methylprednisolone therapy when we consider steroid therapy most appropriate for their condition, before utilizing other antirheumatic, antiinflammatory, or so-called immunomodulatory/immunosuppressive ("second-line") agents. (Note that this form of prednisone unresponsiveness is quite different from generalized glucocorticoid resistance, where patients are resistant to all forms of steroids, and from those with selective responsiveness to betamethasone ${ }^{19}$, and is beyond the scope of this discussion ${ }^{20}$.)

Physicians, especially of the younger generation(s), should be aware of this possible explanation for unexpected prednisone unresponsiveness. We believe it is real, has a scientific basis, and is important in optimally caring for our patients with chronic inflammatory diseases.

\section{DEEPALI SEN, MD, Resident; ROSY RAJBHANDARY, MD, Resident,}

Department of Medicine, Saint Barnabas Medical Center;

ANTHONY CARLINO, $\mathrm{MD}, \mathrm{PhD}$,

Assistant Program Director,

Department of Medicine,

Saint Barnabas Medical Center,

Assistant Professor,

University of Dentistry and Medicine of New Jersey,

New Jersey Medical School,

Livingston, New Jersey;

RONALD J. ANDERSON, MD, MACR,

Associate Professor,

Harvard Medical School,

Division of Rheumatology, Immunology and Allergy,

Department of Medicine,

Brigham and Women's Hospital,

Boston, Massachusetts;

PETER H. SCHUR, MD, MACR,

Professor of Medicine, Personal non-commercial use only. The Journal of Rheumatology Copyright @ 2010. All rights reserved. 
Harvard Medical School,

Division of Rheumatology, Immunology and Allergy,

Department of Medicine,

Brigham and Women's Hospital,

Boston, Massachusetts;

RICHARD S. PANUSH, MD, MACP, MACR,

Professor and Chair,

Department of Medicine, Saint Barnabas Medical Center, University of Dentistry and Medicine of New Jersey, New Jersey Medical School,

Livingston, New Jersey, USA

Address correspondence to Dr.Panush; E-mail:rspanush@sbhcs.com

\section{REFERENCES}

1. Decker JL. Management. In: Schur PH, editor. The clinical management of systemic lupus erythematosus. New York: Grune and Stratton Inc; 1982:265.

2. Hench PS, Kendall EC, Slocumb CH, Polley HF. The effect of a hormone of the adrenal cortex (17-hydroxy-II-dehydrocorticosterone: compound E) and of pituitary adrenocorticotrophic hormone on rheumatoid arthritis. Mayo Clinic Proc 1949; 24:181-97.

3. Polley HF. Discovery of anti-inflammatory effects of cortisone. In: McCarty DJ, editor. Landmark advances in rheumatology. Atlanta: Contact Associates, American Rheumatism Association; 1985:9-12.

4. Richter B, Neises G, Clark C. Glucocorticoid withdrawal schemes in chronic medical disorders. A systematic review. Endocrinol Metabol Clin 2002;31:371-84.

5. Macdonald RG, Panush RS, Pepine CJ. Rationale for use of gluco-corticoids in modification of restenosis after coronary angioplasty. Am J Cardiol 1987;60:56B-60B.

6. Thirumalaiselvan G, Bharucha P, Panush RS. Tapering steroids: art or science? A critical review of evidence-based guidelines for giant cell arteritis and polymyalgia rheumatica. Proceedings of the New Jersey Chapter Scientific Meeting, American College of Physicians, Woodbridge, New Jersey, Jan 2007.

7. Chauhan B, Lahita R, Panush RS. Tapering steroids. In preparation.

8. Burton RB, Keutman EH, Waterhouse C. The conversion of cortisone acetate to other alpha-ketolic steroids. J Clin Endocrinol Metabol 1953;13:48-63.
9. Powell L, Axelson E. Corticosteroids in liver disease. Gut 1972;13:690-6.

10. Madsbad S, Bjerregaard B, Hendriksen JH, Juhl E, Kehlet H. Impaired conversion of prednisone to prednisolone in patients with liver disease. Gut 1980;21:52-6.

11. Davis M, Williams J, Chakraborty J, English J, Marks V, Ideo G, et al. Prednisone or prednisolone for the treatment of chronic active hepatitis. Br J Clin Pharmacol 1978;5:501-5.

12. Jenkins J, Sampson P. Conversion of cortisone to cortisol and prednisone to prednisolone. Br Med J 1967;2:205-7.

13. Taylor NF, Bartlett WA. Corticosteroid 11 reductase deficiency: evidence for a new inborn error in metabolism of adrenal steroids. J Endocrinol 1989;102S:89.

14. Schimmer BP, Parker KL. Adrenocorticotropic hormone. In: Brunton LL, editor. Goodman and Gilman's pharmacological basis of therapeutics. 11th ed. New York: McGraw-Hill Companies; 2006:1601.

15. Draper N, Stewart PL. 11 beta hydroxysteroid dehydrogenase and pre-receptor regulation of corticosteroid hormone action. J Endocrinol 2005;186:251-71.

16. Hardy R, Rabbitt E, Filer A, Emery P, Hewison M, Stewart PM, et al. Local and systemic glucocorticoid metabolism in inflammatory arthritis. Ann Rheum Dis 2008;67:1204-10.

17. Draper N, Walker EA, Bujalska IJ, Tomlinson JW, Chalder SM, Arlt W, et al. Mutations in the genes coding 11 beta hydroxysteroid dehydrogenase type 1 and hexose 6 phosphate dehydrogenase interact to cause cortisone reductase deficiency. Nature Genetics 2003;34:434-9.

18. White P. Genotypes of 11 beta hydroxysteroid dehydrogenase 1 and hexose 6 phosphate dehydrogenase loci are not risk factors for apparent cortisone reductase deficiency in a large population based sample. J Clin Endocrinol Metab 2005;90:5880-3.

19. Barnes PJ, Adcock IM. Glucocorticoid resistance in inflammatory diseases. Lancet 2009;373:1905-17.

20. Drigo I, Piscianz E, Valencic E, De Iudicibus S, Tommasini A, Ventura A, et al. Selective resistance to different glucocorticoids in severe autoimmune disorders. Clin Immunol 2010;134:313-9.

J Rheumatol 2010;37:1559-61; doi:10.3899/jrheum.091260 